Haemorrhoids and a high-fibre diet

SIR,-I read "Prospective trials of minor surgical procedures and high-fibre diet for haemorrhoids" (20 October, p 967) with interest. Mr M R B Keighley and his colleagues concluded that a high-fibre diet was of little value in the management of haemorrhoids. They came to this conclusion after giving patients a high-fibre diet sheet and four Fybranta tablets daily. Each tablet contains $2 \mathrm{~g}$ of bran, so that the daily dose was $8 \mathrm{~g}$. 'This is about half the amount that is required by the average patient to render the stools soft so that they are voided without straining. The makers of Fybranta (Norgine) recommend 6-12 tablets daily. In practice, patients and their diets vary and so each patient has to find the amount of bran that he or she requires to open the bowels without straining. Some need several tablespoons a day. Few benefit from as little as $8 \mathrm{~g}$ of bran daily.

There is no doubt that a high-fibre die relieves the symptoms of early haemorrhoids and makes the postoperative course following dilatation or haemorrhoidectomy more comfortable. Hence it would be a pity if the value of bran in the treatment of haemorrhoids were to be discredited because insufficient bran was given to the patients in this study.

Neil Stamford Painter

Manor House Hospital,
London NW11 $7 \mathrm{HX}$

\section{Day-bed surgery}

SIR,-With the support of my general surgical colleagues, I tried to use some beds of a general surgical allocation for the treatment of patients on a one-day basis over the two years 1975-7. I am now retired and the figures are not readily available to me, but these are scarcely relevant to the points I would like to emphasise.

Information and liaison are the top priorities. General practitioners were invited to commen about the scheme before it was started. The response was generally favourable but there was some fear of calls, especially at night, when perhaps little or no information would be available about the treatment undergone by the patients. It requires scrupulous attention to detail to obviate this difficulty. (1) The general practitioner's agreement should preferably be obtained when a patient is to be selected. (2) The practice should be informed 48 hours before the patient is due to attend. (3) On completion of operation a letter or form typed or filled in legibly should be posted first class not later than the last post of the day. There is no place for the economy of letter pooling for postage.

I thought at first that it would be justifiable in straightforward cases to ask the patient or a relative to take a note to the GP's surgery but this is fraught with risks. It may be necessary to telephone to give more certain early information in some cases.

A form should be as simple as possible but cover details of operation, anaesthetic, likely contingencies, and arrangements for removal of sutures or follow-up. After each minor operation there is pressure to get on with the next case; and even with good secretarial assistance, which I had, ensuring proper completion of a form giving adequate early information was the biggest problem owing to changing junior surgical staff, sometimes not conversant with practice in the UK.

Operative failures or complications cause alarm, irritation, and embarrassment so that the emphasis in operative technique is primarily on care. Reasonable speed comes with practice but haemostasis must not be sacrificed to achieve this. Accommodation was provided in a main ward or a side ward. Occasional difficulties arose when nursing staff changed and were not fully informed of the procedures. Patients were enthusiastic; but selection had to take account of all the circumstances, of which available transport was probably the most important. Much reliance was placed on friends or relatives.

Owing to a changing "on-take" rota for emergencies, a regular day could not be set aside. To achieve results proportionate to the effort involved, it is essential to form a special unit on the lines adopted by the Western General Hospital, Edinburgh (22 September, pp 712 and 714), with regular staff and secretary so that all parties have a full understanding of what is involved. But the scope for this sort of treatment is enormous.

\section{Douglas Vellacott}

Tavistock, Devon

Inflammatory bowel disease in the West Indies

SIR,-The recent article by Professor Courtenay Bartholomew and $\mathrm{Mr}$ Alan Butler (6 October, p 824) reporting the finding of 34 cases of ulcerative colitis and 14 cases of Crohn's disease in indigenes of Trinidad and Tobago over a 10 -year period is interesting. However, the title "Inflammatory bowel disease in the West Indies" is misleading since their data relate only to a single country.

Trinidad and Tobago are small islands in the extreme south of the Caribbean; the former is situated six miles from the South American mainland. Observations made in these islands may not reflect the situation elsewhere. Pockets of disease are known to exist in the West Indies-for example, yellow fever in Trinidad, schistosomiasis in St Lucia and Puerto Rico, and tropical sprue in Puerto Rico, Haiii, and the Dominican Republic.

No cases of Crohn's disease have been reported from Jamaica to date, although ulcerative colitis has been found. ${ }^{1}$ I have heard of one patient from Barbados with Crohn's disease, but know of no case reports from other West Indian countries. The patchy geographical distribution of Crohn's disease worldwide is well recognised. This solitary paper from Trinidad should stimulate more careful case documentation and epidemiological research in the Caribbean.

\section{Communicable Diseases Unit,} St George's Hospital, Terry, S, and Ric;e, D, Abstract from 22nd Scientific
Meeting of the Commonwealth Caribbean Medical Research Council, Belize, 1977.

\section{To skip judiciously}

SIR,-It is no doubt a privilege to have one's work reviewed by your distinguished journal (3 November, p 1133). I wonder, however, whether your distinguished reviewer George Komrower has not confused two quotations.
He quotes Disraeli as having said that "the art of reading is to skip judiciously." The Oxford Dictionary of Quotations (2nd edition) attributes this to Philip Gilbert Hamerton. On the other hand Isaac D'Israeli is quoted as saying, "There is an art of reading as well as an art of thinking and an art of writing."

LEONARD SINCLAIR

London NW11

\section{Beer as prevention for runner's} haematuria

SIR,-Your leading article on runner's haematuria (21 July, p 159) contains no information on its prevention. It was present in $18 \%$ of our members after a recent Boston marathon. ${ }^{1}$ Those of us who have run over 100 marathons have empirical'y used beer to prevent this condition. It appears exclusively in its "benign" form in non-drinkers of beer; however, haematuria in two beer-drinking runners was found to be due to malignancies.

The benign form of runner's haematuria follows exercise-induced renal shut-downeither as ischaemic renal injury or as bruising of the empty bladder. Usually this is selflimited; however, it has resulted in at least one death in the United States. The runner, in his 20 s, had multiple episodes of dark urine in training. Urological studies gave negative results. However, he developed renal shutdown in his first marathon and expired a week later (1 September, p 547).

The diuretic effect of one litre of beer appears adequate to protect a runner during a 40 kilometre run if he has no past history of haematuria or urinary calculi. However, if there is a history of one of these conditions a litre of beer should be used for each 20 kilometres.

T J BASSLER

American Medical Joggers Association,

Centinela Hospital,

Inglewood, California 90307 , Siegel, A J, et al, fournal of the American Medical
Association, 1979, 241, 391.

\section{Routine exercise testing using} bipolar- $\mathrm{CM}_{5}$-lead recordings

SIR,-A recent letter by Drs P A Poole-Wilson and A F Rickards (29 September, p 794) commented on work reported by Dr J A Raffo and others (7 August, p 295). Dr Poole-Wilson and Dr Rickards say, "a fairer assessment of the clinical value of the test studied should include the 32 patients who were excluded. The results would then be less favourable." Such a conclusion cannot be made and was possibly a result of not properly understanding the report. There were 36 patients with indeterminate tests, only six of whom could be made available to a physical training programme so as to allow a proper test-that is, their heart rate after training could be raised to a high enough level to complete the test. "Indeterminate" means the test cannot be completed and therefore they should not be included.

There remains their suggestion that a 12-lead recording system for the electrocardiogram compares favourably with bipolar$\mathrm{CM}_{5}$ recordings and they claim they have shown, "that in patıents with angina pectoris 
the sensitivity of the multi-lead exercise test is greater than that of a single-lead systems." In fact, they have never compared the 12-lead system with $\mathrm{CM}_{5}$ but only with $\mathrm{V}_{5}$ lead; we pointed out (7 August, p 295) that the use of this lead results in appreciable errors.

Dr Poole-Wilson and Dr Rickards mention three published reports, ${ }^{1-3}$ firstly, in the wrong context and, secondly, with inaccuracy. The first report constitutes a letter on data comparing single-conventional-lead recordings (including $\mathrm{V}_{5}$ lead) and combined-conventionallead recordings, ${ }^{2}$ and the second report uses similar analysis. ${ }^{2}$ These reports cannot be used to compare results obtained using $\mathrm{CM}_{5}$ with those obtained from conventional multi-lead system. ${ }^{*}$ The third report concerns a comparison of conventional- $\mathrm{V}_{5}$-lead to conventional 11 lead electrocardiographs, bipolar leads $\left(\mathrm{CM}_{5}, \mathrm{CC}_{5}, \mathrm{CL}\right)$ and to all 14 leads; in the context of a carefully selected group of patients with typical angina pectoris (the largest group studied) this report has in fact shown that sensitivity of $\mathrm{CM}_{5}$ was $79 \%$ in comparison with that of $76 \%$ in the conventional 11-lead system.

In our paper we made only two points: that using lead $\mathrm{CM}_{\mathrm{F}}$ allows as great an accuracy of diagnosis as the conventional " 12 leads" and is indeed simpler and easier to use as stated in the original article; and that all patients with indeterminate tests trained on a fitness programme have subsequently been able to complete the test. Our results obtained since that investigation support the above conclusions.

$R$ J LINDEN

D A S G MARY

Department of Cardiovascular Studies,

Leeds LS2 $9 \mathrm{JT}$

${ }^{1}$ Phibbs, B P, and Buckels, L J, American Heart Fournal, 1975, 90, 275

${ }^{2}$ Mason, R E, et al, Circulation, 1967, 26, 517.

${ }^{3}$ Chaitman, B, et al, Circulation, $1979, \mathbf{5 9}, 560$

4 Baron, D W, Poole-Wilson, P A, and Rickards, A F, British Heart fournal, 1979, 41, 364.

\section{The injured liver}

SIR,- - How much I agree with all the points in your leading article on the injured liver (20 October, p 954). However, I would like to add two further problems that can occur. ${ }^{1}$

Firstly, in the supine position the weight of the liver can control bleeding from hepatic veins that have been avulsed from the inferior vena cava; but as soon as the liver at operation is lifted to assess the damage there will in these circumstances be massive venous bleeding, which is very difficult to control. Secondly, there may be intrahepatic damage causing progressive bleeding over a period of days until the tension within the peritoneal capsule becomes so great that the liver suddenly "explodes," causing instant death.

JOHN PIPER

General (Sister Dora) Hospital,

Walsall, Staffs

${ }^{1}$ Lester, J C, and Piper, J V, Nursing Times, 25 June $1970, \mathrm{p} 818$.

\section{Treatment of chronic paronychia}

SIR,-We would be grateful for the opportunity to comment on the advice given on the treatment of chronic paronychia (20 October, $p$ 980). The underlying cause of this condition is generally agreed to be prolonged exposure to (cold) water. Both Candida and Pseudomonas species may then act as opportunist pathogens. The mainstay of treatment must be the removal of the underlying cause so far as practicable, and specific chemotherapy may then be indicated. As treatment may be prolonged we would advocate, where possible, collection of material for laboratory investigation before antimicrobial chemotherapy is commenced.

Further, we were alarmed to read that clotrimazole and miconazole are accorded the role of antibacterial agents. While these imidazoles are potent antifungal drugs, their respective manufacturers do not claim activity against Gram-negative bacteria. Both drugs display some in-vitro activity against Grampositive bacteria and the manufacturer of miconazole claims an in-vivo effect. We know of no published evidence to substantiate this assertion and in our experience the clinical effect is unsatisfactory. ${ }^{1}$

K A V Cartwright L J R MILNE

Central Microbiological Laboratories,

Western General Hospital,

Edinburgh EH4 2XU

R A HARDIE

Department of Dermatology,

Royal Infirmary,
Edinburgh EH3 9 YW

${ }^{1} \mathrm{McVie}, \mathrm{D} \mathrm{H}$, Cartwright, K A V, and Milne, L J R, British fournal of Clinical Practice, 1978, 32, 353 .

\section{Maternal mortality}

SIR,-Minerva, commenting on the latest Report on Confidential Enquiries into Maternal Deaths in England and Wales ${ }^{1}$ (27 October, p 1079), suggests that "until some way is found to persuade more British women of the importance of early booking, our obstetric record will compare unfavourably with the rest of Western Europe."

As we have been reminded ad nauseam, France has all but conquered the problem of late booking by introducing financial incentives (more than 30 years ago). So why is it that the risk of maternal death in England and Wales is half that in France (and, incidentally, between a third and a quarter of that in Italy and West Germany)'? In response, I would hope that Minerva might wish to point out that international comparisons of crude mortality statistics is a thoroughly unsound basis on which to make judgments about our obstetric record. But then that leaves me wondering about the basis of her belief that "our obstetric record compares unfavourably with the rest of Western Europe."

\section{IAIN Chalmers}

National Perinatal Epidemiology Unit, Churchill Hospital,
Oxford OX3 7LJ

epartment of Health and Social Security, Report on Eonfidential Enquiries into Maternal Deaths in England ${ }^{2}$ Report of the Royal Commission on the National Health
Service, Cmnd 7615, p 23. London, HMSO, 1979.

\section{Prophylactic thiamine in liquor}

SIR,- - In your report of a symposium on genetics (27 October, p 1059), Dr Charles R Scriver is quoted as saying that the original suggestion of preventing Wernicke's encephalopathy by the addition of small quan- tities of thiamine to all liquor (1 September, p 549) would make the drinks taste terrible and give rise to an unsavoury body odour.

Our recent research at the Hollybush Inn (sic) has shown that the addition of thiamine $\mathrm{BP}$, in the concentration suggested $(5 \mathrm{mg} /$ pint beer and $50 \mathrm{mg} /$ bottle whisky) could not be tasted in a double-blind crossover trial using a well-known bitter beer and neat whisky. Furthermore, following the trial our wives did not complain more of our body odour than on a control day. This research was not grant aided.

The Campaign for Real Ale has objected strongly, saying that thiamine is an unnatural and expensive additive. This vitamin is produced by yeasts during the process of fermentation and is present, in small quantities, in any undistilled alcoholic drink. The additional cost would be less than $0 \cdot 1 \mathrm{p}$ per pint-a small price to pay for the number of brains that might be saved.

GARETH JONES MARTIN BRISCOE

Tegfan Day Hospital, Cardiff CF4 7XB

\section{The national filth}

SiR,-Dr T D V Swinscow (20 October, p 999) rightly draws attention to the squalid state of Southampton airport and, as your leading article (p 952) points out, might have commented in similar vein on roads, public buildings, railways, and beauty spots. However, before being too critical of other institutions the medical profession should perhaps set about putting its own house in order.

Recently, and not during a period of strikes, I visited a London teaching hospital and a large hospital on the outskirts of London. In both the grounds and area surrounding the entrances were grubby and strewn with litter. The management and staff generally seemed unconcerned or perhaps were powerless to do anything about it. I could not help feeling the same attitudes prevailed inside- the hospitals, where cleanliness and discipline are surely important.

You suggest schoolchildren should spend one period a month clearing the district surrounding their schools. In our district at least, before doing this many of them could well start on their own playing fields, which are among the dirtiest areas in the town. The idea of introducing a swingeing deposit on packaging has been in operation in Oregon, USA, for some years and has been very successful in reducing litter as well as helping to save energy and raw materials by recycling bottles, cans, and other waste. The rule of law probably fails because it is cumbersome. On-the-spot fines have worked well in Singapore and Australia and could be operated here by the police and perhaps traffic wardens. Fines from such a source could be used to augment the pay of those involved or to support local charities.

May I make a number of additional suggestions? Much of the cardboard, sheets of plastic, and industrial debris of infinite variety which make our motorways so unpleasant come from improperly covered lorries. It should be easy to trace their owners and impose such fines as would make an effective tarpaulin cover a good investment. In other countries shops, restaurants, pubs, amusement 